Figure 1. Mapping of national surveillance systems in Europe
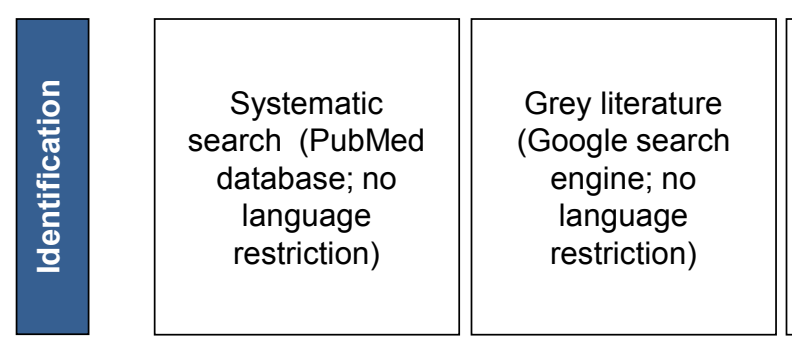

Relevant national websites,

ministries of

health, institutes

of public health,

ECDC and WHO
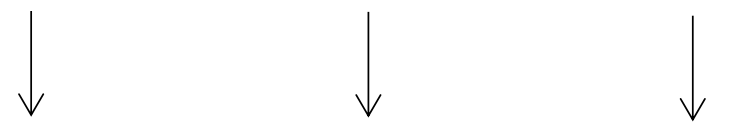

Preliminary catalogue of surveillance efforts in Europe ${ }^{* *}$

Surveillance systems' protocol requests

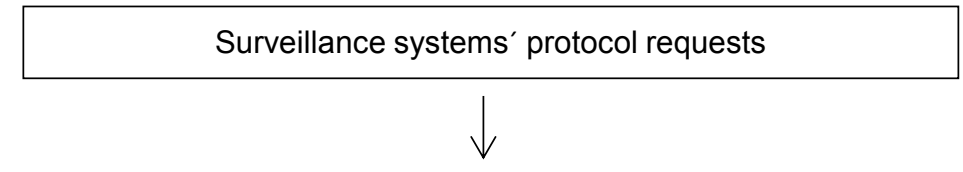

Data review by national surveillance experts

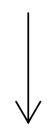

\section{Data extraction}

(information pertaining to surveillance framework)

38 surveillance systems from 19 countries

(Online protocol available, 26; protocol obtained after request,

$$
\text { 12) }
$$

PubMed search example:

"Antimicrobial resistan*" OR "Antibiotic resistan*" OR "Multidrug resistan*" AND Surveillance [MeSH Terms] AND Germany [MeSH Terms] NOT reviews AND ("last 10 years"[PDat])

Inclusion criteria: Systems* promoted or endorsed by a regional, national or transnational official health organisations or scientific society, reporting data for at least one year period since 2006; with the availability of methodology for our review

Exclusion criteria: Systems without access to their surveillance methodology; privately funded surveillance programmes; national reference centres/ quality registers; outbreak monitoring programmes; mandatory reporting systems were excluded.

\section{Limitations}

- EUCIC and other experts suggestions

- Information unavailable from 13 European countries ${ }^{* *}$

- Translation bias (many surveillance systems offer information only in local language) 